\title{
Persistent Reflux Symptoms in the Proton Pump Inhibitor Era: The Changing Face of Gastroesophageal Reflux Disease
}

\author{
EVAN S. DELLON and NICHOLAS J. SHAHEEN
}

Center for Esophageal Diseases and Swallowing and Center for Gastrointestinal Biology and Disease, Division of Gastroenterology and Hepatology, Department of Medicine, University of North Carolina School of Medicine, Chapel Hill, North Carolina

G iven the widespread use of potent acid suppressive therapies and primary caregivers' increasing comfort with prescribing these medications at high doses, the patient population presenting to gastroenterologists for symptoms of gastroesophageal reflux disease (GERD) has changed. Whereas previous consultation often revolved around the control of erosive disease and other mucosal manifestations of GERD, and terminated with the prescription of proton pump inhibitor (PPI) therapy, gastroenterologists often now only enter the scene after failure of PPI therapy, for symptoms either resistant or only partially responsive to these medications. Because of the high proportion of subjects with esophagitis who are healed with PPI, ${ }^{1,2}$ upper endoscopy of such individuals is low yield, ${ }^{3}$ with only a small minority demonstrating erosive disease.

The care of such patients is challenging. High-quality evidence supporting useful diagnostic testing or alternative effective therapies is largely lacking. However, the number of subjects with GERD symptoms incompletely or nonresponsive to PPI therapies is high, and their utilization of healthcare resources is substantial. The purpose of this mini-review is to examine the definition and epidemiology of esophageal GERD symptoms incompletely responsive to PPI therapy, the potential pathophysiologic mechanisms behind these symptoms, the differential diagnosis and evaluation of such patients, and current and developing therapeutic options.

\section{Definition and Epidemiology}

Incomplete response of classic GERD symptoms, such as heartburn and regurgitation, to PPI therapy is common. A recent American Gastroenterological Association survey of $>1000$ subjects receiving PPI therapy for GERD symptoms demonstrated that $38 \%$ reported residual symptoms, and that more than half of those with residual symptoms took additional medication to control symptoms, most commonly over-the-counter antacids (47\%). ${ }^{4}$ A systematic review of symptom control in trials of PPI therapy for GERD demonstrated that only a minority of subjects with GERD achieved complete symptom control on therapy. ${ }^{5}$ Interestingly, this analysis demonstrated that subjects entering GERD trials as nonerosive patients were less likely to achieve symptom control than were erosive patients (37\% vs $57 \% ; P<.001)$.
Despite the common nature of incomplete control of GERD symptoms on PPI therapy, a universal definition for "PPI-refractory GERD" is lacking. Is a subject PPI refractory after incomplete control at once daily dosing? Should twice daily (BID) or other regimens be required before a subject is considered refractory? Previous work demonstrates that a substantial number of subjects (as high as $32 \%$ ) on daily PPI continue to demonstrate abnormal distal esophageal acid exposures, and that this proportion can be lowered to single digits by increasing standard therapy to BID PPI. ${ }^{6,7}$ However, US Food and Drug Administration-approved dosing of these medications does not extend to BID therapy. Because BID therapy is commonly employed and has been recommended as a therapeutic trial in subjects refractory to once daily therapy, ${ }^{8}$ for purposes of this discussion, refractory subjects will be considered as having troublesome symptoms despite BID PPI therapy.

The Montreal classification defines GERD as "a condition which develops when the reflux of stomach contents causes troublesome symptoms and/or complications." 9 Which symptoms are considered "troublesome" is left to the discretion of the patient. This classification further divides GERD into esophageal and extraesophageal syndromes, and subdivides esophageal syndromes as those manifest with esophageal injury, such as esophagitis, stricture, or Barrett's esophagus, and those manifest solely by troublesome symptoms. In such a scheme, a subject with heartburn and an incomplete response to PPI, who had no history of mucosal disease on or off therapy, in whom GERD was causing bothersome symptoms, would be classified as a nonerosive typical esophageal reflux patient.

\section{Differential Diagnosis of Residual Reflux Symptoms on PPI}

When patients have symptoms of ongoing reflux despite maximal PPI therapy, the main clinical question is: Are these symptoms related to gastroesophageal reflux? There is a broad differential diagnosis to consider, and potential etiologies may be gastrointestinal (GI) or

C 2010 by the AGA Institute

$0016-5085 / \$ 36.00$

doi:10.1053/j.gastro.2010.05.016 
non-GI related. The GI etiologies can be esophageal or nonesophageal, and the former may be reflux or nonreflux related. There are 3 major categories of refluxrelated causes. First is reflux with ongoing acid exposure. Etiologies include incorrect medication dose timing, medication noncompliance, residual pathologic acid secretion, rapid PPI metabolism, a hypersecretory state, a significant anatomic abnormality like a large hiatal hernia, excess reflux during transient lower esophageal sphincter relaxations (tLESRs), or defective esophageal mucosal barrier function. Second is reflux of nonacid material from either the stomach or the duodenum (e.g., bile). Third is reflux of normal amounts of weakly acidic or alkaline contents into a hypersensitive esophagus.

The non-reflux-related esophageal causes include dysmotility syndromes such as achalasia, esophageal spasm, or scleroderma; eosinophilic esophagitis; pill esophagitis; and infectious esophagitis. In the absence of structural, motility, or inflammatory causes, functional heartburn or function chest pain should be considered, depending on the primary symptom.

It is beyond the scope of this mini-review to discuss the nonesophageal causes of reflux-type symptoms in detail, but typical conditions to consider include gallbladder disease, malignancy in the GI system or surrounding organs, cardiovascular disease, and musculoskeletal disease.

\section{Mechanisms of Persistent Reflux Symptoms}

The putative mechanisms of PPI-refractory GERD symptoms are illustrated in Figure 1. Similar to the differential diagnosis for symptoms, the mechanisms can be either reflux or non-reflux related.

\section{Elevated Acid Exposures Despite Therapy}

As noted, relatively few patients maintain pathologic levels of esophageal acid exposure despite appropriately administered BID therapy. ${ }^{6,7}$ There are several mechanisms to explain elevated esophageal acid exposures despite PPI therapy. First, there may be medication noncompliance. Only $60 \%-67 \%$ of PPI prescriptions are actually filled, and compliance with medication is $<50 \%$ at 1 year after prescription. ${ }^{10}$ A related issue is whether the medication is taken correctly. The PPI must be activated within the parietal cell canaliculus for binding with the H-K ATPase. ${ }^{11}$ Because the greatest number of pumps are present in the preprandial state, the typical recommendation is to administer the medication before breakfast. ${ }^{11,12}$ Despite instruction, more than half of patients dose PPIs suboptimally. ${ }^{13}$

Another explanation may be related to PPI metabolism. Although individual PPIs are metabolized by different hepatic cytochrome isoenzymes, there is patient-level variability in drug metabolism. It is conceivable that a "rapid" PPI metabolizer might not achieve high enough serum levels for adequate acid suppression, ${ }^{14-16}$ but this is likely a small proportion of treatment failures. Nocturnal acid breakthrough is also related to PPI metabolism, and may be responsible for persistent symptoms in some patients, ${ }^{17}$ but the correlation between symptoms and acid exposures is poor. ${ }^{18}$

In the correct clinical context, for example if small bowel ulceration accompanies refractory reflux and diarrhea, a hypersecretory state such as Zollinger-Ellison syndrome could be considered. However, this remains an uncommon cause of refractory reflux, and PPIs are the recommended initial treatment for Zollinger-Ellison syndrome. ${ }^{19}$

A final mechanism involves disruption of the antireflux barrier at the gastroesophageal junction, due to either a hiatal hernia or a hypotensive lower esophageal sphincter (LES). A number of medications and foods (eg, anticholinergics, estrogens, calcium-channel blockers, nitroglycerine, benzodiazepines, chocolate, caffeine, alcohol, peppermint) cause decreased LES pressures..$^{20,21}$

\section{Transient Lower Esophageal Sphincter Relaxations}

tLESRs are the major mechanism of both physiologic and pathologic reflux. ${ }^{22-24}$ They differ from swallow-induced LES relaxations in that they are not associated with an esophageal peristaltic wave and the duration of LES relaxation is longer. ${ }^{25}$ Gastric distention, mediated by a vagal reflex arc, can prompt tLESRs, allowing for venting gas and, in patients with reflux disease, the reflux of gastric contents. ${ }^{24,26}$

PPIs do not have any effect on tLESRs; they are acidsuppressive medications, but do not inhibit the reflux of gastric contents. In patients where tLESRs are the predominant pathophysiologic mechanism of reflux, PPIs may neutralize gastric acid, but do not affect the underlying cause. The observation that tLESRs can be inhibited by gamma aminobutyric acid receptor type B (GABA) agonists, however, has opened new therapeutic possibilities (see below). ${ }^{27,28}$

\section{Reflux of Nonacidic Gastroduodenal Contents}

PPIs convert acidic refluxate to nonacidic refluxate. ${ }^{29}$ However, reflux of nonacidic fluid can also be associated with symptoms of reflux. Combined multichannel intraluminal impedance and $\mathrm{pH}$ monitoring allows detection of nonacid reflux. ${ }^{30-32}$ This technology is able to characterize patients with ongoing reflux symptoms, but negative traditional $\mathrm{pH}$ testing because impedance monitoring can identify reflux of gas, mixed refluxate, and weakly or nonacid reflux. ${ }^{33-35}$ Such reflux events may be promoted by tLESRs, hypotensive LES, a gastroesophageal junction anatomic defect, or a combination of these factors. ${ }^{36}$ Higher proximal extent of refluxate and 


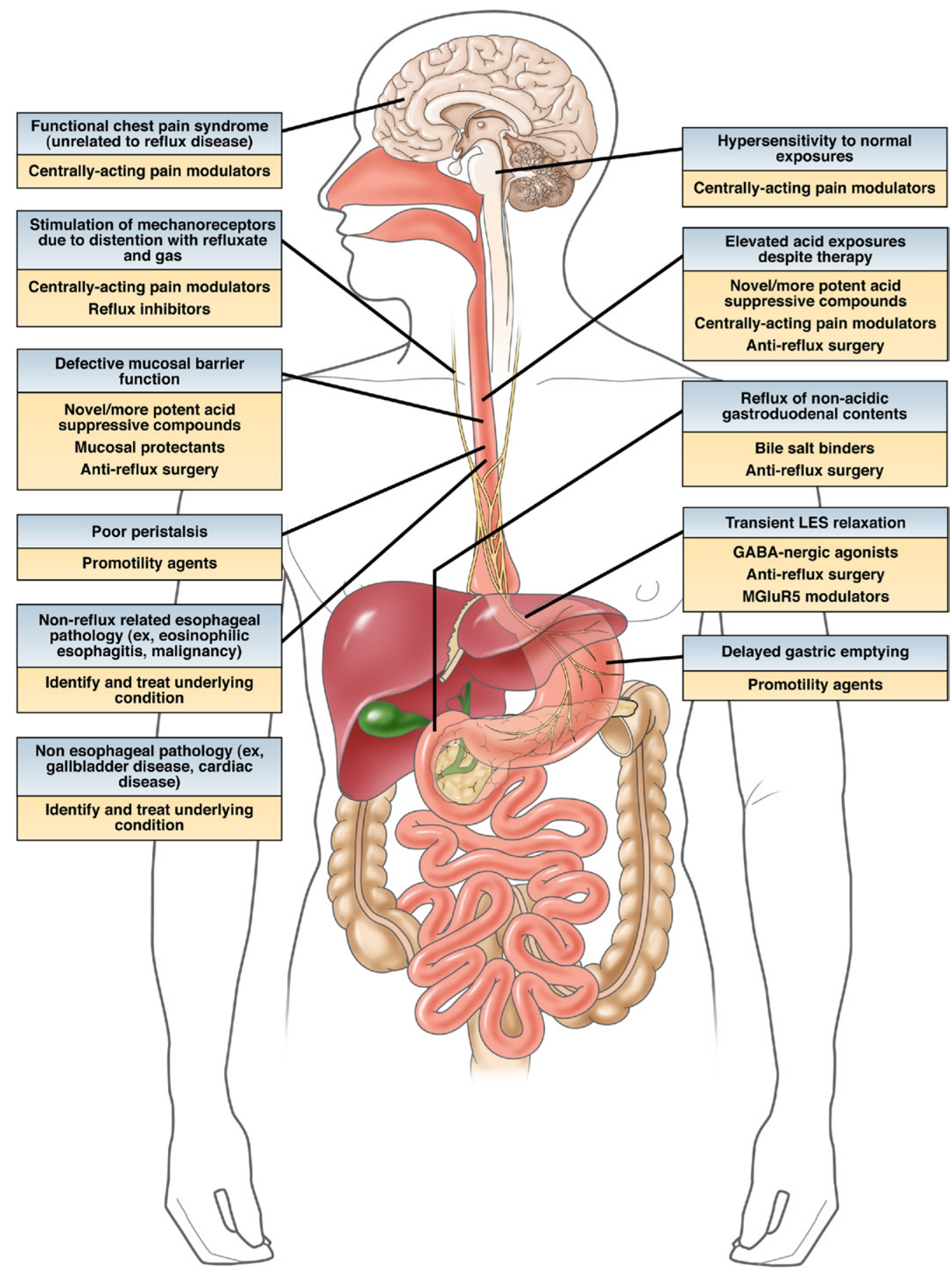

Figure 1. Putative etiologies of PPI-refractory GERD symptoms and potential therapies. Each of the eleven boxes describes a potential mechanism for PPI-refractory GERD symptoms (blue shading) with corresponding therapies targeting this mechanism (orange shading). The mechanism is also linked to the anatomic area of interest (solid black line).

reflux of mixed gaseous/liquid content are primary determinants of symptom generation. ${ }^{37}$

Bile acid reflux is also a potential cause of residual symptoms. Bile reflux can potentiate erosive esophagitis caused by an acidic refluxate, as well cause PPI-refractory reflux symptoms in the absence of acid exposure. ${ }^{38,39}$

\section{Simulation of Mechanoreceptors Owing to Distention With Refluxate and Gas}

Esophageal mechanoreceptors mediate stretch stimuli, and may be responsible for reflux symptoms. ${ }^{40}$ In healthy volunteers, heartburn and chest pain can be in duced through activation of mechanoreceptors by bal- 
loon distension ${ }^{41}$ in a process that can be independent of the presence of acid, ${ }^{42,43}$ or exacerbated by it. ${ }^{44}$ Some patients with functional heartburn may have sensitization of these receptors as a mechanism of their symptoms. ${ }^{40,42}$ In addition, stimulation of mechanoreceptors may trigger a vagally mediated reflux arc that induces cough, bronchospasm, or other extraesophageal symptoms. ${ }^{36,45-47}$

\section{Defective Mucosal Barrier Function}

The nonkeratinized, stratified squamous esophageal epithelium provides a robust physical barrier against material of wide-ranging temperature, $\mathrm{pH}$, and osmolality. The ultrastructure of the esophageal mucosa has been well described, and although complexes of tight junctions are responsible for the majority of barrier function, ${ }^{48,49}$ basolateral chloride/bicarbonate exchangers also rapidly normalize intracellular $\mathrm{pH} .{ }^{50}$ In addition to prolonged acid exposure, factors such as increasing hyperosmolality of oral intake, smoking, and ethanol may lead to mucosal barrier dysfunction. ${ }^{51-53}$

\section{Hypersensitivity to Normal Exposures}

A subset of patients with symptoms of reflux and normal upper endoscopies have normal esophageal acid exposures but a strong correlation between physiologic reflux events and symptoms. ${ }^{33,34,40}$ Visceral hypersensitivity is likely the underlying mechanism, ${ }^{54}$ although the exact pathophysiology is unknown. One candidate for local modulation of symptoms is an acid-sensing receptor in the transient receptor potential cation channel class. ${ }^{40}$ In preliminary studies, the capsaicin or vanilloid receptor 1 is localized in sensory neurons, causes burning pain in response to an acid stimulus, and has been shown to have increased expression in esophagitis patients. ${ }^{55,56}$

\section{Poor Peristalsis and Delayed Gastric Emptying}

If esophageal luminal clearance of noxious stimuli is impaired, then ongoing symptoms may result. In addition to gravity, the major mechanism of esophageal luminal clearance is peristalsis. ${ }^{49}$ Underlying etiologies to consider include aperistalsis, ineffective esophageal motility, and esophageal spasm..$^{20,57}$ Similarly, if there is gastric dysmotility from gastroparesis of any etiology and the stomach does not empty in a timely fashion, not only can ongoing gastric distention trigger tLESRs, but the increased volume of gastric contents themselves may promote reflux. ${ }^{24}$

\section{Functional Heartburn/Chest Pain Syndrome}

In the absence of other mechanisms, it is common for reflux symptoms to be functional in nature. Indeed, in recent studies more than half of the PPI-refractory reflux symptom population did not have evidence of any gastroesophageal reflux on combined $\mathrm{pH} /$ impedance testing. ${ }^{33-35}$ The Rome III criteria for functional heartburn are (1) burning retrosternal discomfort or pain; (2) absence of evidence of that gastroesophageal acid reflux is the cause of the symptom; (3) absence of histopathology-based esophageal motility disorders; and (4) that the criteria are fulfilled for the last 3 months with symptom onset $\geq 6$ months before diagnosis. ${ }^{58}$ Although the basis of these symptoms is unknown, it is believed that the pathophysiology involves visceral hypersensitivity and altered central nervous system pain modulation, often in the setting of psychologic comorbidity. ${ }^{58-60}$

\section{Diagnostic Evaluation of Persistent Symptoms}

For patients with esophageal reflux symptoms that persist on PPI therapy, the goal is to determine whether there is reflux disease, what the mechanism might be, and if there is not reflux disease, to perform other appropriate evaluation (Figure 2). After consideration of serious non-GI pathology and ensuring correct medication dosing, upper endoscopy is performed. It is important to recognize the yield of this procedure for structural disease is low, with only $0.2 \%$ of patients having esophageal cancer, $<10 \%$ with persistent esophagitis, and $5 \%-10 \%$ with Barrett's esophagus. ${ }^{3,17,61,62}$ It is also reasonable to perform at least five esophageal biopsies to exclude eosinophilic esophagitis, even if the esophageal mucosa seems to be normal. ${ }^{63,64}$ Eosinophilic esophagitis has been reported in $1 \%-8 \%$ of the PPI-refractory patient population undergoing upper endoscopy. ${ }^{3,65-69}$ If the upper endoscopy is normal, then the character and acidity of esophageal refluxate is determined. $\mathrm{pH} /$ impedance testing is most useful in this context., ${ }^{83-35}$ High-resolution esophageal manometry can also be considered at this point because esophageal dysmotility may manifest with reflux symptoms, but the yield of this test in this setting is unclear. $8,57,70$

Whether $\mathrm{pH} /$ impedance should be performed on or off PPI therapy is a matter of debate, and some subjects may ultimately undergo the examination twice, once off therapy and once on, to gain a more complete understanding of their reflux profile. , $33-35,70-73$ If there is ongoing esophageal acid exposure on therapy, then the patient truly has refractory acid reflux and may be a candidate for further intensification of medical therapy, or consideration of operative therapy. In the appropriate clinical context, an evaluation for gastrinoma should be considered. If there is excess nonacidic reflux that correlates with symptoms, then the patient has nonacid reflux, which may be the etiology of the symptoms. If there is no evidence of pathologic acidic reflux, but symptoms correlate strongly with physiologic reflux, then the patient has a hypersen- 


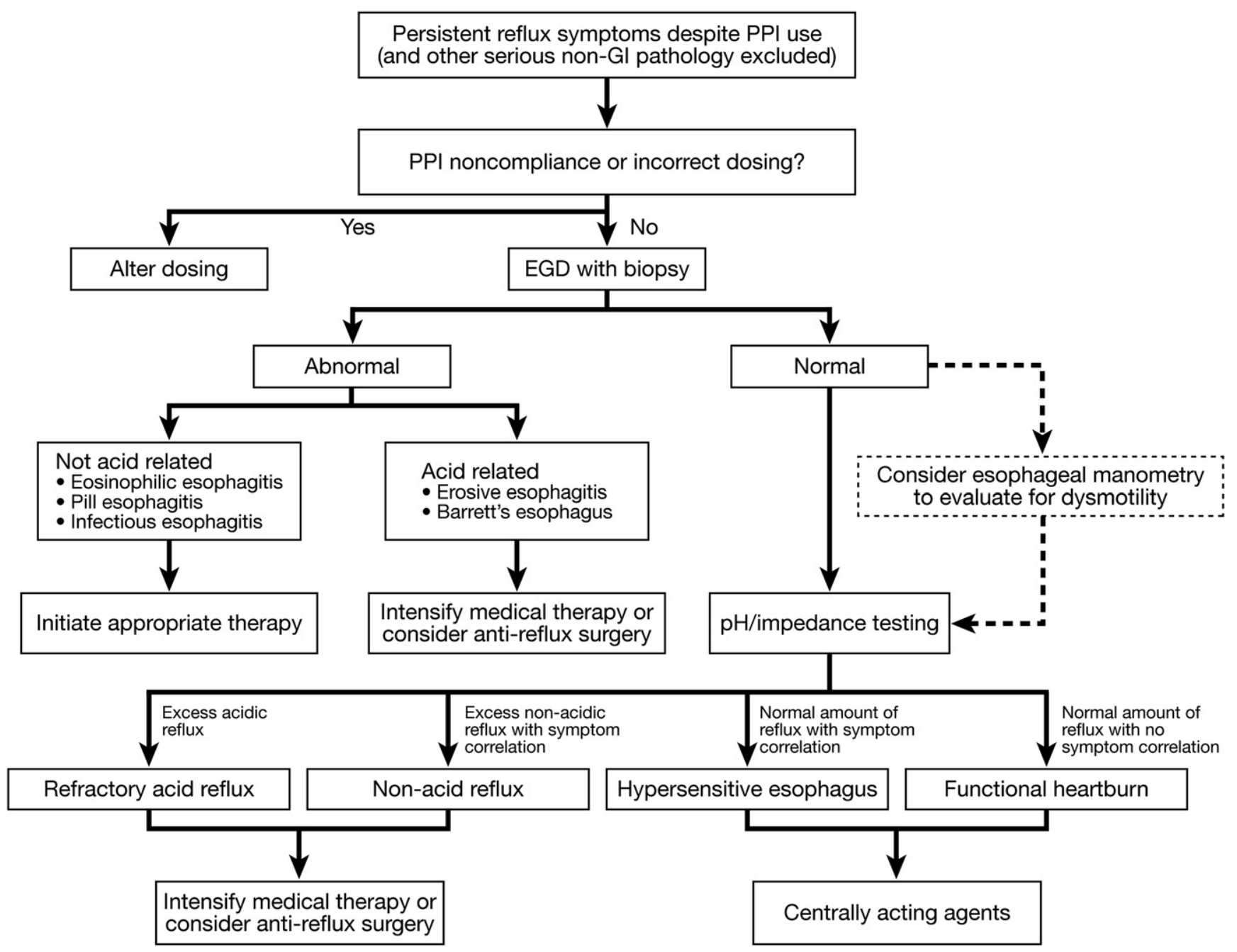

Figure 2. An approach to diagnosis and treatment of the patient with PPI-refractory GERD symptoms. After excluding serious non-GI pathology and ensuring proper medication use, upper endoscopy with biopsy is performed. If the upper endoscopy is abnormal, either an acid-related or nonacid-related etiology is determined. If the upper endoscopy is normal, then the character and acidity of esophageal refluxate is determined with $\mathrm{pH} / \mathrm{impedance}$ testing. At this point, esophageal manometry can also be considered. If $\mathrm{pH} /$ impedance testing reveals excess acid reflux, then the patient has refractory acid reflux and treatment is either intensification of medical therapy or consideration of surgery. If there is excess nonacidic reflux, which correlates with symptoms, then the patient has nonacid reflux; therapeutic considerations are the same. If there is a normal amount of reflux, but symptoms correlate strongly with physiologic reflux, then the patient has a hypersensitive esophagus. Finally, if there is a normal amount of reflux with no symptom correlation, then the patient does not have reflux and likely has functional heartburn or functional chest pain, or a nonesophageal etiology should be considered. For each of these last 2 scenarios, centrally acting agents are typically prescribed.

sitive esophagus. Finally, if there is neither pathologic reflux nor symptom correlation, then the patient does not have reflux and other causes should be sought. In this situation, functional heartburn or functional chest pain is the most common diagnosis. ${ }^{33-35,58}$

\section{Therapeutic Options}

As noted, the escalation of PPI therapy beyond BID dosing is of unproven utility, and the vast majority of GERD subjects on BID dosing normalize esophageal acid exposures. Although early work suggested that the addition of nighttime $\mathrm{H} 2$ receptor antagonists was ben- eficial, ${ }^{74}$ follow-up studies demonstrated early tolerance limiting utility, ${ }^{75}$ and routine administration of nighttime H2 blocker is not recommended. ${ }^{8}$ Several classes of medications have been proposed as adjunct therapy for subjects with residual symptoms on PPI (Figure 1). Although some of these therapies have data supporting their use as monotherapy in the setting of GERD, data supporting their use as adjunct therapy with PPI are largely lacking. The therapy chosen corresponds with the presumed mechanism(s) of the residual GERD symptoms, and options can be divided into those currently available, and those under development. 


\section{Currently Available}

Among the currently available therapeutic options for the treatment of GERD symptoms are (1) conversion to a different/more potent acid suppressive regimen, (2) bile salt binders, (3) promotility agents, (4) baclofen, (5) mucosal protectants, and (6) centrally acting pain modulators, such as tricyclic agents.

Although data support modest differences between the PPIs with respect to healing rates for mucosal disease when given in once daily doses, ${ }^{1,2}$ no data demonstrate a benefit in switching from 1 brand to another in symptomatic nonerosive patients already receiving BID dosing. Some data do suggest that in subjects refractory to once daily PPI, a switch to a different once daily PPI may be as effective as BID therapy with the initial agent, and such a therapeutic trial may be warranted in the subject refractory to once daily PPI before institution of BID therapy. ${ }^{76}$ Otherwise, further manipulation of PPI dosing is not likely to be fruitful. In healthy volunteers, discontinuation of PPI therapy has been shown to cause increased reflux symptoms (termed rebound acid hypersecretion). ${ }^{77}$ Although the impact of medication discontinuation in the PPI-refractory patient population is not well described, it seems prudent to avoid starting and stopping PPI therapy in nonerosive patients who do not respond to this class of medications. ${ }^{77,78}$

Administration of bile salt binders assumes reflux of bile salts in the acid suppressed patient exacerbates esophageal pain. No data support the efficacy of adding bile salt binders in this clinical setting.

Although promotility agents might address poor peristalsis as well as gastroparesis as potential etiologies of worsened reflux, there is currently a paucity of available well-tolerated promotility agents. Given the side effect profile of metoclopramide ${ }^{79}$ and its unclear efficacy as an antireflux agent, its use as an adjunct to PPI therapy cannot be advocated. Similarly, the side effect profile and tachyphylaxis observed with erythromycin use make this a poor choice for chronic therapy. In short, although a promotility agent is conceptually appealing, currently available therapeutics are lacking.

Baclofen is a GABA B receptor agonist that inhibits tLESRs. This medication has the theoretical advantage of inhibiting acidic, nonacidic, and mixed reflux. In placebocontrolled studies, baclofen decreases esophageal acid exposures in the short term as monotherapy, although its value as an adjunct to PPI therapy administered chronically is unclear. ${ }^{80}$ Its significant side effect profile (dizziness, nausea, vomiting, somnolence, and other central nervous system symptoms) is generally reversible on cessation of therapy.

Mucosal protectants, such as sucralfate, may be given empirically as adjuncts to PPI therapy. Such medications are well tolerated, but their short dwell time in the esophagus and lack of proven efficacy in combination with PPI make their incremental benefit unclear.

Centrally acting agents such as tricyclic antidepressants are attractive candidates, owing both to their painmodulating properties as well as the treatment of any underlying depressive symptoms. Although data substantiate the potential for these therapeutic agents in a related condition, noncardiac chest pain, ${ }^{81}$ few data are available in PPI-refractory GERD or functional heartburn. A small uncontrolled series of subjects with persistent GERD symptoms but no objective evidence of ongoing reflux following Nissen fundoplication demonstrated a 50\% response to tricyclics. ${ }^{82}$

Surgical antireflux procedures are unquestionably effective at diminishing episodes of reflux and improving symptomatology in subjects with documented reflux disease. However, subjects completely unresponsive to PPI therapy have demonstrated poorer outcomes after antireflux surgery, ${ }^{83}$ and caution is advised in the consideration of this procedure in such a patient. A recent series of subjects with normal esophageal acid exposures but abnormal impedance suggests that impedance monitoring may aid in the selection of PPI-refractory subjects who benefit from surgical antireflux procedures. ${ }^{84}$

\section{Under Development}

Several agents currently under development may augment our current limited therapeutic choices in PPI refractory patients. The development of more potent acid suppression may aid the small proportion of subjects with persistently elevated acid exposures despite PPI therapy. Potassium-competitive acid blockers work through competitive inhibition of the H-K ATPase of parietal cells. While pharmacodynamic studies suggest that these agents should have rapid onset of vigorous acid suppression, randomized data to date do not show superiority over PPIs in subjects with nonerosive disease. ${ }^{85}$ New GABA B receptor agonists are currently under development, which may allow the beneficial effects of a baclofen-like compound, without the same degree of central side effects. ${ }^{86,87}$ Metabotropic glutamate receptor-5 (MGluR5) modulators decrease the occurrence of tLESRs and increase LES pressure. Proof-of-principle studies demonstrate that administration of a MGluR5 modulator was associated with a decrease in number and duration of symptomatic reflux episodes in subjects with GERD. ${ }^{88}$

\section{Conclusion}

Persistent reflux symptoms in the face of PPI therapy are common in subjects treated for GERD, and most subjects will not demonstrate pathologically elevated acid exposures. Multiple pathophysiologic mechanisms have been proposed to account for these persistent symptoms. The diagnostic evaluation of subjects with 
persistent reflux symptoms while on PPIs revolves around excluding alternative diagnoses and isolating the likely mechanism(s) of symptoms. A variety of therapeutic modalities are available to the physician and may be tailored to the symptom complex and postulated mechanism of the residual symptoms. In general, scant literature is available on which to base therapeutic decisions. Several new classes of medications are under investigation, which may alter our approach to the management of these subjects.

\section{Supplementary Material}

Note: The first 5 references associated with this article are available below in print. The remaining references accompanying this article are available online only with the electronic version of the article. To access the remaining references, visit the online version of Gastroenterology at www.gastrojournal.org, and at doi:10.1053/ j.gastro.2010.05.016.

\section{References}

1. Castell DO, Kahrilas PJ, Richter JE, et al. Esomeprazole (40 mg) compared with lansoprazole $(30 \mathrm{mg})$ in the treatment of erosive esophagitis. Am J Gastroenterol 2002;97:575-583.

2. Kahrilas PJ, Falk GW, Johnson DA, et al. Esomeprazole improves healing and symptom resolution as compared with omeprazole in reflux oesophagitis patients: a randomized controlled trial. The Esomeprazole Study Investigators. Aliment Pharmacol Ther 2000; 14:1249-1258.

3. Poh $\mathrm{CH}$, Gasiorowska A, Navarro-Rodriguez T, et al. Upper Gl tract findings in patients with heartburn in whom proton pump inhibitor treatment failed versus those not receiving antireflux treatment. Gastrointest Endosc 2010;71:28-34.

4. AGA. GERD patient study: Patients and their medications. Available at: http://www.gastro.org/user-assets/documents/13 Media/GERD_Survey_Final_Report_2.pdf,2008. Accessed March 24, 2010.

5. Dean BB, Gano AD, Jr., Knight K, et al. Effectiveness of proton pump inhibitors in nonerosive reflux disease. Clin Gastroenterol Hepatol 2004;2:656-664.

\section{Reprint requests}

Address requests for reprints to: Nicholas J. Shaheen, MD, MPH, CB\#7080, Bioinformatics Building, 130 Mason Farm Road, UNC-CH, Chapel Hill, NC 27599-7080. e-mail: nshaheen@med.unc.edu; fax: (919) 843-2508.

\section{Conflicts of interest}

The authors disclose the following: Nicholas J. Shaheen receives research funding from AstraZeneca, BARRX Medical, CSA Medical, Oncoscope Procter \& Gamble, and Takeda, and is a consultant for AstraZeneca, CSA Medical, Oncoscope, and Takeda. Evan S. Dellon receives investigator-initiated research funding from AstraZeneca. 


\section{References (Online Only)}

6. Bajbouj M, Becker V, Phillip V, et al. High-dose esomeprazole for treatment of symptomatic refractory gastroesophageal reflux disease-a prospective $\mathrm{pH}$-metry/impedance-controlled study. Digestion 2009;80:112-118.

7. Charbel S, Khandwala F, Vaezi MF. The role of esophageal pH monitoring in symptomatic patients on PPI therapy. Am J Gastroenterol 2005;100:283-289.

8. Kahrilas PJ, Shaheen NJ, Vaezi MF. American Gastroenterological Association Institute technical review on the management of gastroesophageal reflux disease. Gastroenterology 2008;135: 1392-1413.

9. Vakil N, van Zanten SV, Kahrilas $P$, et al. The Montreal definition and classification of gastroesophageal reflux disease: a global evidence-based consensus. Am J Gastroenterol 2006;101: 1900-1920.

10. El-Serag HB, Fitzgerald S, Richardson P. The extent and determinants of prescribing and adherence with acid-reducing medications: a national claims database study. Am J Gastroenterol 2009;104:2161-2167.

11. Wolfe MM, Sachs G. Acid suppression: optimizing therapy for gastroduodenal ulcer healing, gastroesophageal reflux disease, and stress-related erosive syndrome. Gastroenterology 2000; 118:S9-31.

12. Robinson M. Review article: the pharmacodynamics and pharmacokinetics of proton pump inhibitors-overview and clinical implications. Aliment Pharmacol Ther 2004;20(suppl 6):1-10.

13. Gunaratnam NT, Jessup TP, Inadomi J, et al. Sub-optimal proton pump inhibitor dosing is prevalent in patients with poorly controlled gastro-oesophageal reflux disease. Aliment Pharmacol Ther 2006;23:1473-1477.

14. Furuta $T$, Shirai $N$, Sugimoto $M$, et al. Influence of CYP2C19 pharmacogenetic polymorphism on proton pump inhibitor-based therapies. Drug Metab Pharmacokinet 2005;20:153-167.

15. Klotz U. Impact of CYP2C19 polymorphisms on the clinical action of proton pump inhibitors (PPIs). Eur J Clin Pharmacol 2009;56: $1-2$.

16. Hunfeld NG, Mathot RA, Touw DJ, et al. Effect of CYP2C19*2 and *17 mutations on pharmacodynamics and kinetics of proton pump inhibitors in Caucasians. Br J Clin Pharmacol 2008;65: 752-760.

17. Fass R, Sifrim D. Management of heartburn not responding to proton pump inhibitors. Gut 2009;58:295-309.

18. Nzeako UC, Murray JA. An evaluation of the clinical implications of acid breakthrough in patients on proton pump inhibitor therapy. Aliment Pharmacol Ther 2002;16:1309-1316.

19. Osefo N, Ito T, Jensen RT. Gastric acid hypersecretory states: recent insights and advances. Curr Gastroenterol Rep 2009;11: 433-441.

20. Kahrilas PJ. Clinical practice. Gastroesophageal reflux disease. N Engl J Med 2008;359:1700-1707.

21. Tutuian R. Adverse effects of drugs on the esophagus. Best Pract Res Clin Gastroenterol 2010;24:91-97.

22. Dodds WJ, Dent J, Hogan WJ, et al. Mechanisms of gastroesophageal reflux in patients with reflux esophagitis. N Engl J Med 1982;307:1547-1552.

23. Allen ML, Castell JA, DiMarino AJ, Jr.Mechanisms of gastroesophageal acid reflux and esophageal acid clearance in heartburn patients. Am J Gastroenterol 1996;91:1739-1744.

24. Pandolfino JE, Zhang QG, Ghosh SK, et al. Transient lower esophageal sphincter relaxations and reflux: mechanistic analysis using concurrent fluoroscopy and high-resolution manometry. Gastroenterology 2006;131:1725-1733.

25. Holloway RH, Penagini R, Ireland AC. Criteria for objective definition of transient lower esophageal sphincter relaxation. Am J Physiol 1995;268:G128-133.
26. Pandolfino JE, Ghosh SK, Zhang Q, et al. Upper sphincter function during transient lower oesophageal sphincter relaxation (tLOSR); it is mainly about microburps. Neurogastroenterol Motil 2007;19:203-210.

27. Lehmann A, Antonsson M, Bremner-Danielsen M, et al. Activation of the $\mathrm{GABA}(\mathrm{B})$ receptor inhibits transient lower esophageal sphincter relaxations in dogs. Gastroenterology 1999;117: 1147-1154.

28. Lehmann A, Antonsson M, Holmberg AA, et al. (R)-(3-amino-2fluoropropyl) phosphinic acid (AZD3355), a novel GABAB receptor agonist, inhibits transient lower esophageal sphincter relaxation through a peripheral mode of action. J Pharmacol Exp Ther 2009; 331:504-512.

29. Vela MF, Camacho-Lobato L, Srinivasan R, et al. Simultaneous intraesophageal impedance and $\mathrm{pH}$ measurement of acid and nonacid gastroesophageal reflux: effect of omeprazole. Gastroenterology 2001;120:1599-1606.

30. Srinivasan R, Vela MF, Katz PO, et al. Esophageal function testing using multichannel intraluminal impedance. Am J Physiol Gastrointest Liver Physiol 2001;280:G457-462.

31. Tutuian R, Vela MF, Shay SS, et al. Multichannel intraluminal impedance in esophageal function testing and gastroesophageal reflux monitoring. J Clin Gastroenterol 2003;37:206-215.

32. Vela MF. Non-acid reflux: detection by multichannel intraluminal impedance and $\mathrm{pH}$, clinical significance and management. Am J Gastroenterol 2009;104:277-280.

33. Mainie I, Tutuian R, Shay S, et al. Acid and non-acid reflux in patients with persistent symptoms despite acid suppressive therapy: a multicentre study using combined ambulatory impedance-pH monitoring. Gut 2006;55:1398-1402.

34. Zerbib F, Roman S, Ropert A, et al. Esophageal pH-impedance monitoring and symptom analysis in GERD: a study in patients off and on therapy. Am J Gastroenterol 2006;101:1956-1963.

35. Sharma N, Agrawal A, Freeman J, et al. An analysis of persistent symptoms in acid-suppressed patients undergoing impedance-pH monitoring. Clin Gastroenterol Hepatol 2008;6:521524.

36. Richter JE. Role of the gastric refluxate in gastroesophageal reflux disease: acid, weak acid and bile. Am J Med Sci 2009; 338:89-95.

37. Tutuian R, Vela MF, Hill EG, et al. Characteristics of symptomatic reflux episodes on Acid suppressive therapy. Am J Gastroenterol 2008;103:1090-1096.

38. Tack J, Koek G, Demedts I, et al. Gastroesophageal reflux disease poorly responsive to single-dose proton pump inhibitors in patients without Barrett's esophagus: acid reflux, bile reflux, or both? Am J Gastroenterol 2004;99:981-988.

39. Siddiqui A, Rodriguez-Stanley S, Zubaidi S, et al. Esophageal visceral sensitivity to bile salts in patients with functional heartburn and in healthy control subjects. Dig Dis Sci 2005;50:8185.

40. Ang D, Sifrim D, Tack J. Mechanisms of heartburn. Nat Clin Pract Gastroenterol Hepatol 2008;5:383-392.

41. Patel RS, Rao SS. Biomechanical and sensory parameters of the human esophagus at four levels. Am J Physiol 1998;275:G187191.

42. Fass R, Naliboff B, Higa L, et al. Differential effect of long-term esophageal acid exposure on mechanosensitivity and chemosensitivity in humans. Gastroenterology 1998;115:1363-1373.

43. DeVault KR. Acid infusion does not affect intraesophageal balIoon distention-induced sensory and pain thresholds. Am J Gastroenterol 1997;92:947-949.

44. Peghini PL, Johnston BT, Leite LP, et al. Mucosal acid exposure sensitizes a subset of normal subjects to intra-oesophageal balloon distension. Eur J Gastroenterol Hepatol 1996;8:979_ 983. 
45. Canning BJ, Mazzone SB. Reflex mechanisms in gastroesophageal reflux disease and asthma. Am J Med 2003;115 Suppl 3A:45S-48S.

46. Vaezi MF. Atypical manifestations of gastroesophageal reflux disease. MedGenMed 2005;7:25.

47. Kollarik M, Brozmanova M. Cough and gastroesophageal reflux: insights from animal models. Pulm Pharmacol Ther 2009;22: 130-134.

48. Orlando RC, Lacy ER, Tobey NA, et al. Barriers to paracellular permeability in rabbit esophageal epithelium. Gastroenterology 1992;102:910-923.

49. Orlando RC. Pathogenesis of gastroesophageal reflux disease. Am J Med Sci 2003;326:274-278.

50. Tobey NA, Reddy SP, Khalbuss WE, et al. $\mathrm{Na}(+)$-dependent and -independent $\mathrm{Cl}$-/HCO3- exchangers in cultured rabbit esophageal epithelial cells. Gastroenterology 1993;104:185-195.

51. Orlando RC, Bryson JC, Powell DW. Effect of cigarette smoke on esophageal epithelium of the rabbit. Gastroenterology 1986;91: 1536-1542.

52. Long JD, Marten E, Tobey NA, et al. Effects of luminal hypertonicity on rabbit esophageal epithelium. Am J Physiol 1997;273: G647-654.

53. Bor S, Caymaz-Bor C, Tobey NA, et al. Effect of ethanol on the structure and function of rabbit esophageal epithelium. Am J Physiol 1998;274:G819-826.

54. Rao SS, Gregersen H, Hayek B, et al. Unexplained chest pain: the hypersensitive, hyperreactive, and poorly compliant esophagus. Ann Intern Med 1996;124:950-958.

55. Caterina MJ, Julius D. The vanilloid receptor: a molecular gateway to the pain pathway. Annu Rev Neurosci 2001;24:487-517.

56. Matthews PJ, Aziz Q, Facer P, et al. Increased capsaicin receptor TRPV1 nerve fibres in the inflamed human oesophagus. Eur J Gastroenterol Hepatol 2004;16:897-902.

57. Pandolfino JE, Ghosh SK, Rice J, et al. Classifying esophageal motility by pressure topography characteristics: a study of 400 patients and 75 controls. Am J Gastroenterol 2008;103:27-37.

58. Galmiche JP, Clouse RE, Balint A, et al. Functional esophageal disorders. Gastroenterology 2006;130:1459-1465.

59. Rubenstein JH, Nojkov B, Korsnes S, et al. Oesophageal hypersensitivity is associated with features of psychiatric disorders and the irritable bowel syndrome. Aliment Pharmacol Ther 2007; 26:443-452.

60. Mizyed I, Fass SS, Fass R. Review article: gastro-oesophageal reflux disease and psychological comorbidity. Aliment Pharmacol Ther 2009;29:351-358.

61. Dickman R, Mattek N, Holub J, et al. Prevalence of upper gastrointestinal tract findings in patients with noncardiac chest pain versus those with gastroesophageal reflux disease (GERD)-related symptoms: results from a national endoscopic database. Am J Gastroenterol 2007;102:1173-1179.

62. Voutilainen M, Sipponen P, Mecklin JP, et al. Gastroesophageal reflux disease: prevalence, clinical, endoscopic and histopathological findings in 1,128 consecutive patients referred for endoscopy due to dyspeptic and reflux symptoms. Digestion 2000;61: 6-13.

63. Furuta GT, Liacouras CA, Collins MH, et al. Eosinophilic esophagitis in children and adults: a systematic review and consensus recommendations for diagnosis and treatment. Gastroenterology 2007;133:1342-1363.

64. Dellon ES, Farrell TM, Bozymski EM, et al. Diagnosis of eosinophilic esophagitis after fundoplication for 'refractory reflux': implications for preoperative evaluation. Dis Esophagus 2009 Oct 26 [Epub ahead of print].

65. Liacouras CA, Wenner WJ, Brown K, et al. Primary eosinophilic esophagitis in children: successful treatment with oral corticosteroids. J Pediatr Gastroenterol Nutr 1998;26:380-385.
66. Rodrigo S, Abboud G, Oh D, et al. High intraepithelial eosinophil counts in esophageal squamous epithelium are not specific for eosinophilic esophagitis in adults. Am J Gastroenterol 2008; 103:435-442.

67. Veerappan GR, Perry JL, Duncan TJ, et al. Prevalence of eosinophilic esophagitis in an adult population undergoing upper endoscopy: a prospective study. Clin Gastroenterol Hepatol 2009;7: $420-426$.

68. Sa CC, Moraes-Filho JP, Eisig JN, et al. Low prevalence of eosinophilic esophagitis in patients with refractory gastroesophageal reflux disease: A prospective study. Gastroenterology 2009; 136(suppl 1):S1870.

69. Foroutan M, Norouzi A, Molaei M, et al. Eosinophilic esophagitis in patients with refractory gastroesophageal reflux disease. Dig Dis Sci 2010;55:28-31.

70. Wilson JA, Vela MF. New esophageal function testing (impedance, Bravo $\mathrm{pH}$ monitoring, and high-resolution manometry): clinical relevance. Curr Gastroenterol Rep 2008;10:222-230.

71. Blondeau K, Tack J. Pro: impedance testing is useful in the management of GERD. Am J Gastroenterol 2009;104:26642666.

72. Richter JE. Con: impedance-pH testing does not commonly alter management of GERD. Am J Gastroenterol 2009;104:26672669.

73. Shay S. A balancing view: impedance-pH testing in GERD-limited role for now, perhaps more helpful in the future. Am J Gastroenterol 2009;104:2669-2670.

74. Peghini PL, Katz PO, Castell DO. Ranitidine controls nocturnal gastric acid breakthrough on omeprazole: a controlled study in normal subjects. Gastroenterology 1998;115:1335-1339.

75. Fackler WK, Ours TM, Vaezi MF, et al. Long-term effect of H2RA therapy on nocturnal gastric acid breakthrough. Gastroenterology 2002;122:625-632.

76. Fass R, Sontag SJ, Traxler B, et al. Treatment of patients with persistent heartburn symptoms: a double-blind, randomized trial. Clin Gastroenterol Hepatol 2006;4:50-56.

77. Reimer C, Sondergaard B, Hilsted L, et al. Proton-pump inhibitor therapy induces acid-related symptoms in healthy volunteers after withdrawal of therapy. Gastroenterology 2009;137:80-87.

78. McColl KE, Gillen D. Evidence that proton-pump inhibitor therapy induces the symptoms it is used to treat. Gastroenterology 2009:137:20-22.

79. Miller LG, Jankovic J. Metoclopramide-induced movement disorders. Clinical findings with a review of the literature. Arch Intern Med 1989;149:2486-2492.

80. Ciccaglione AF, Marzio L. Effect of acute and chronic administration of the GABA B agonist baclofen on 24 hour pH-metry and symptoms in control subjects and in patients with gastro-oesophageal reflux disease. Gut 2003;52:464-470.

81. Cannon RO, 3rd, Quyyumi AA, Mincemoyer R, et al. Imipramine in patients with chest pain despite normal coronary angiograms. N Engl J Med 1994;330:1411-1417.

82. Velanovich V. Tricyclic antidepressants in the treatment of postoperative antireflux surgery symptoms. Dig Liver Dis 2005;37: 458.

83. Campos GM, Peters JH, DeMeester TR, et al. Multivariate analysis of factors predicting outcome after laparoscopic Nissen fundoplication. J Gastrointest Surg 1999;3:292-300.

84. Becker V, Bajbouj M, Waller K, et al. Clinical trial: persistent gastro-oesophageal reflux symptoms despite standard therapy with proton pump inhibitors-a follow-up study of intraluminalimpedance guided therapy. Aliment Pharmacol Ther 2007;26: 1355-1360.

85. Dent J, Kahrilas PJ, Hatlebakk J, et al. A randomized, comparative trial of a potassium-competitive acid blocker (AZD0865) and esomeprazole for the treatment of patients with nonerosive reflux disease. Am J Gastroenterol 2008;103:20-26. 
86. Boeckxstaens GE, Rydholm H, Lei A, et al. Effect of lesogaberan, a novel GABA-receptor agonist, on transient lower esophageal sphincter relaxations in male subjects. Aliment Pharmacol Ther Epub March 42010.

87. Gerson LB, Huff FJ, Hila A, et al. Arbaclofen placarbil decreases postprandial reflux in patients with gastroesophageal reflux disease. Am J Gastroenterol 2009 Dec 29 [Epub ahead of print].

88. Keywood C, Wakefield M, Tack J. A proof-of-concept study evaluating the effect of ADX10059, a metabotropic glutamate receptor-5 negative allosteric modulator, on acid exposure and symptoms in gastro-oesophageal reflux disease. Gut 2009;58:1192-1199. 